\title{
AN ECONOMIC CASE FOR DRAINAGE FOR SUSTAINABLE IRRIGATION: CASE STUDIES IN THE LOWER VAAL AND RIET CATCHMENTS
}

\author{
RJ Armour \& MF Viljoen \\ Department of Agricultural Economics, University of the Free State
}

\begin{abstract}
Where evaporation exceeds precipitation salinisation is inevitable. This paper presents a multidisciplinary framework of the dynamic interactions between the hydrology, bio-physical and economics of irrigated agriculture in a semi arid area. Status quo drainage and cropping situations are compared to a scenario of increased drainage and leaching and subsequent higher value crops. Stochastically generated hydrology data fitted to a salinisation:yield production function is inputted in a crop enterprise budget (CEB) simulation model.

Results show losses due to salinisation of up to R6 962/ha, which exceed the direct costs of installing drainage to control salinisation. Although feasible, farmers at this stage of degradation often do not have the financial ability to repay the loans. Where losses do not exceed the financial costs of drainage, soils are further degrading, higher value crops cannot be planted and potential benefits are lost to society, motivating a green box grant. A macro-economic analysis reveals that the potential benefits to society of drainage can repay the total cost of all necessary drainage in a short period of time.
\end{abstract}

JEL Q15, 51

\section{1 Introduction}

Irrigation farmers in the Orange-Vaal and Orange-Riet Water Users Associations (OV \& OR WUAs) are currently faced with many changes, such as increasing environmental controls, pressure to increase water-use efficiency, diminishing returns, increasing debt burdens, the shift in agricultural support from commercial to emerging farmers and a deteriorating resource base (i.e. increasing soil salinisation and water-logging). One management measure that has been identified as able to improve the productivity of irrigation farms affected by salinisation and the long term sustainability of irrigation as a whole is irrigation drainage combined with controllable salt leaching. However, because of the challenges they face, these farmers are in an unsustainable financial position. They are unable to afford the infrastructure required for these measures.
This paper is based on a WRC project entitled Multi-dimensional Models for the Sustainable Management of Water Quantity and Quality in the Orange-Vaal-Riet Convergence System (Viljoen et al., 2006). This research project aimed to fill a current void in research on the economic impact of salinisation, and within a multidisciplinary framework explored the dynamic interactions between the hydrology, bio-physical nature and socio-economy of irrigated agriculture in the Orange-Vaal-Riet convergence system, at the levels of the region as a whole, of the areas managed by the individual Water Users Associations (WUAs), of each irrigation block (sub-WUA) and at a per hectare level.

This paper focuses on the method used in this research project to motivate irrigation drainage as a means of sustainably managing soil salinisation. Thus we will only discuss scenarios of leaching and drainage, and only on the per hectare and irrigation block level. (For results at the regional level, see the full report by Viljoen et al., (2006), 
which shows an input-output analysis and develops a socio-economic welfare index to that evaluate scenarios based on the economic, social and environmental impact of salinisation.)

This paper first presents a case for irrigation drainage and leaching, and then gives an overview of the study area and the research method used to determine the impact of salinisation in the study area. An integrated model for this impact is mathematically specified, and the main results discussed. Recommendations, a summary and a conclusion are then presented.

\section{2}

\section{A case for irrigation drainage and leaching}

The results of a study by Volschenk, Fey and Zietsman (2005) support drainage installation as the most sustainable soil-salinisation management option from a bio-physical perspective. Their results indicate that salts in the irrigation water are not a significant problem; rather, soil salinisation due inter alia to mineralisation of salts already in the soil in arid irrigation areas does pose a serious threat to the long-term sustainability of irrigation on that land. Already, higher-lying areas irrigated with good quality Orange River water are causing salinisation in lower-lying areas. Effective irrigation drainage (including carefully controlled leaching) is the solution recommended by Volschenk et al. (2005).

Both Volschenk et al. (2005) and Armour and Viljoen (2002) agree that the river water quality itself is not a major concern, nor the cause of salinisation. Salinisation is predominantly a natural process that occurs insidiously over time on irrigated land where evapo-transpiration exceeds precipitation.

Historically, the consequences of salinisation led to the demise of the ancient Egyptian and Mesopotamian irrigation-based civilizations (Cowen 2002; Khan, Tariq, Yuanlai \& Blackwell, 2004) and more recently the ecological disasters and collapse of the Aral Sea irrigation project in Kazakhstan (Perry \& Vanderklein, 1996; Wichelns 1999; Cai, McKinney \& Rosegrant, 2003) and the Salton Sea irrigation project in California (Van Schilfgaarde, 2004; Cohen \& Hyun, 2006).

If incorrectly managed, or left unattended, salinisation can lead to financial, social and environmental degradation, and threaten the major contribution that irrigation in arid areas makes to national food security. Salinisation management is therefore arguably a public good, which means that responsibility for its minimisation and sustainability rests with the government.

In recent world trade talks, elimination of agricultural subsidisation has been a major topic. However, also important on these agendas are "green box" taxes, which are promoted to shift the attention of governments and farmers from market manipulation to sustainability enhancement. Thus though subsidisation is frowned upon, sustainability grants for installing irrigation drainage are arguably a new type of acceptable state support.

3

\section{The study area}

Figure 1 presents the basic hydrology network of the study area for this research project. This network correlates with the Water Resources Planning Model (WRPM) used to generate the stochastic hydrology and related salinity scenarios.

The figure shows the positions of the subWUAs that make up the four main irrigation blocks as set up for the hydrology simulation model (i.e. the WRPM) along the rivers and canals in the hydrology network. Hydrologically, the study area is defined in relation to the following rivers:

- Vaal River: downstream of the Bloemhof Dam to the confluence with the Orange River;

- Orange River: the Orange-Riet and OrangeVaal Canal extraction points downstream of the Vanderkloof Dam to the Orange-Vaal Confluence where the return-flows of the study area re-enter the Orange River; and

- Riet River: downstream of the Kalkfontein Dam, including the confluence with the Modder River to the confluence with the Vaal River.

This encompasses the Orange-Vaal (OV) and Orange-Riet (OR) Water Users Associations (WUAs). 


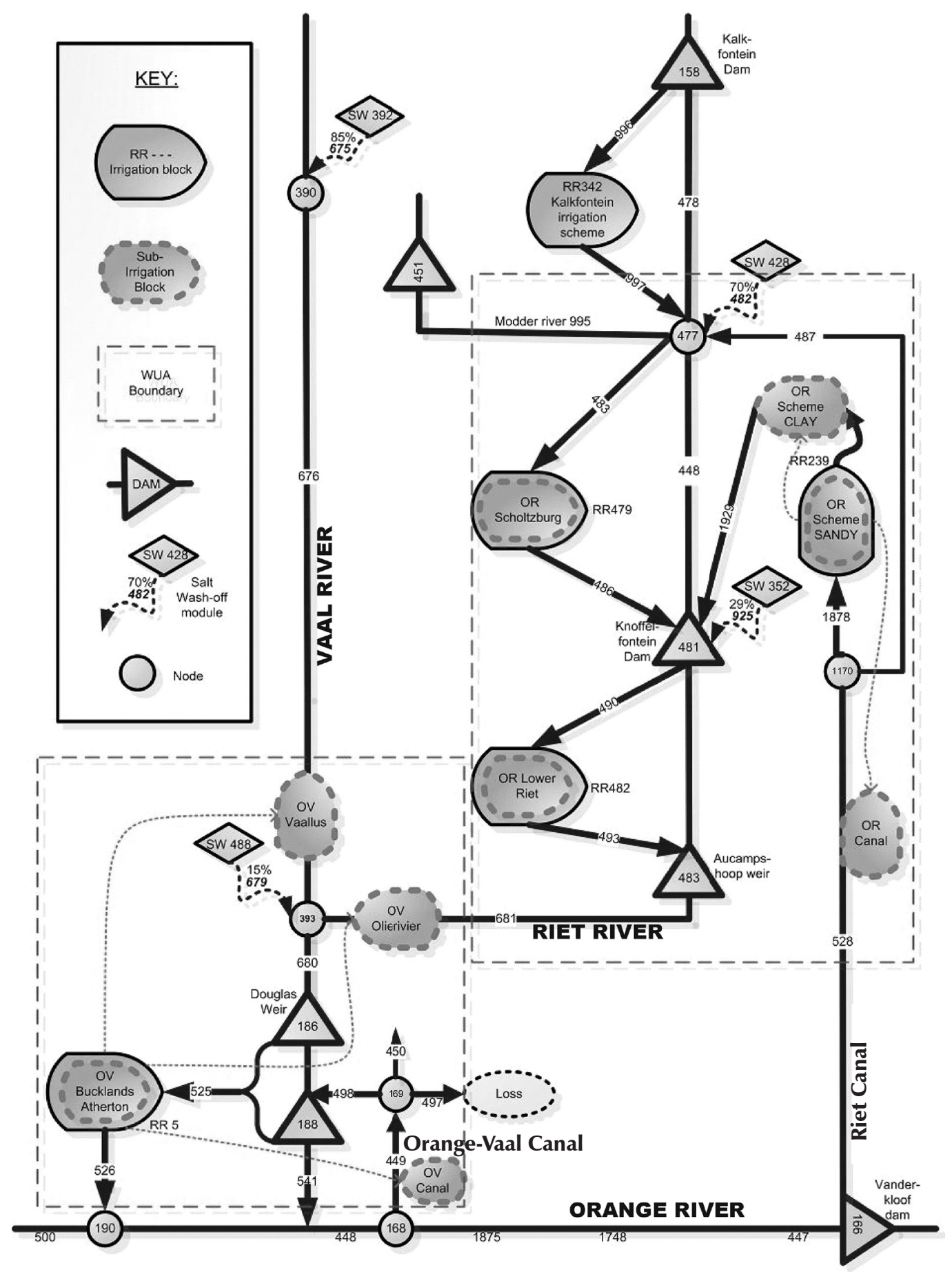

Figure 1

A simplified diagram of the WRPM hydrology set-up of the study area (indicating channels, nodes, irrigation blocks, WUAs and sub-irrigation blocks) 
At micro-hydrology level (as set up for the WRPM), four irrigation blocks in the two WUAs represent the main receiving water quality areas modelled within the Orange-Vaal-Riet-Modder confluence area, namely:

- the Riet River Scheme, Orange Riet Canal and Ritchie sub-WUAs of the OR-WUA, all receiving Orange River water directly from the Orange Riet Canal, combined make up the Rscm irrigation block;

- the Schotzburg sub-WUA of the OR-WUA, lying mainly at the confluence of the Modder and Riet Rivers but receiving a large portion of Orange River water diluting the tail ends of the Riet and Modder Rivers upstream, forming the Rszg irrigation block;

- the Lower Riet River sub-WUA of the OR-WUA, stretching from Ritchie to Soutpansdrift in the Riet River, and mainly receiving Riet Scheme and Scholtzburg return flows, forming the RloR irrigation block; and

- the whole Orange Vaal WUA, constituting the Vall irrigation block, which receives Vaal River system excess spillage and a large portion of Orange River water pumped via the Orange-Vaal and Orange-Riet Canals, with the latter carrying the return-flows of the whole OR-WUA that lies upstream.

Certain characteristics of the study area are identified as of particular importance for integrated salinity modelling. Firstly, these factors influence the anthropogenic (social, political, economic) and natural (bio-physical, hydrology, environment) dynamics of the study area over time and space:

- the spatial dimensions and boundaries spanning two provinces,

- various municipal management areas,

- the confluence of the two major rivers in South Africa,

- various quaternary catchments and

- different water management areas.

Secondly, according to Van Veele (2004), the Riet-Modder catchment is a "feast or famine" catchment with only 8 years in 50 being "average" years. This means that actual simulations from a range of stochastic simulation results must be analysed, not just average values.

4

Method

Many models exist for the dynamics of water use and control, in various disciplines and at various levels. Thus, to develop a framework that holistically integrates these models, we need to move from the traditional single-discipline approach to a more mutli-orI interdisciplinary approach. As McKinney et al. (2000) put it, "the dynamics of water use, pollution and control are so tightly interwoven by a multitude of external factors that the traditional style of mono-disciplinary research is no longer suited to achieve overall satisfactory results."

The aim of the micro-economic salinity simulation (SMsim) suite of models is to integrate holistically the bio-physical components/ processes (including the hydrology) involved in irrigation salinisation into a long-term (dynamic) economic model. The objective of this is to improve the financial sustainability of irrigation agriculture while also ensuring social and environmental sustainability.

This paper only aims to briefly sketch the integrated framework, and discuss the parts of it applicable to per hectare and irrigation block level results for a single leaching and drainage scenario compared to the base case (status quo) over a projected 15 year period.

\subsection{Integrated conceptual framework}

Figure 2 is a schematic diagram of the components of SMsim and its links with the hydrology model (WRPM) and the regional economic model. Crop enterprise budget (CEB) data and subWUA description data are also fed into SMsim to provide the financial drivers and resource composition differences between WUAs.

The profitability of different farm management options can be calculated for the various different hydrology cycles and associated irrigation water salinity regimes. The farm management option identified is a change in crop composition to less salt-sensitive higher value crops, but this is only possible with improved leaching and drainage practices. 
The base case and the scenario in two forms, called 3 and $3+$, are discussed below as hydrology model inputs, with the progressive calculation and flow of data included to micro-economic model output and policy recommendation level.

\section{SMsim design}

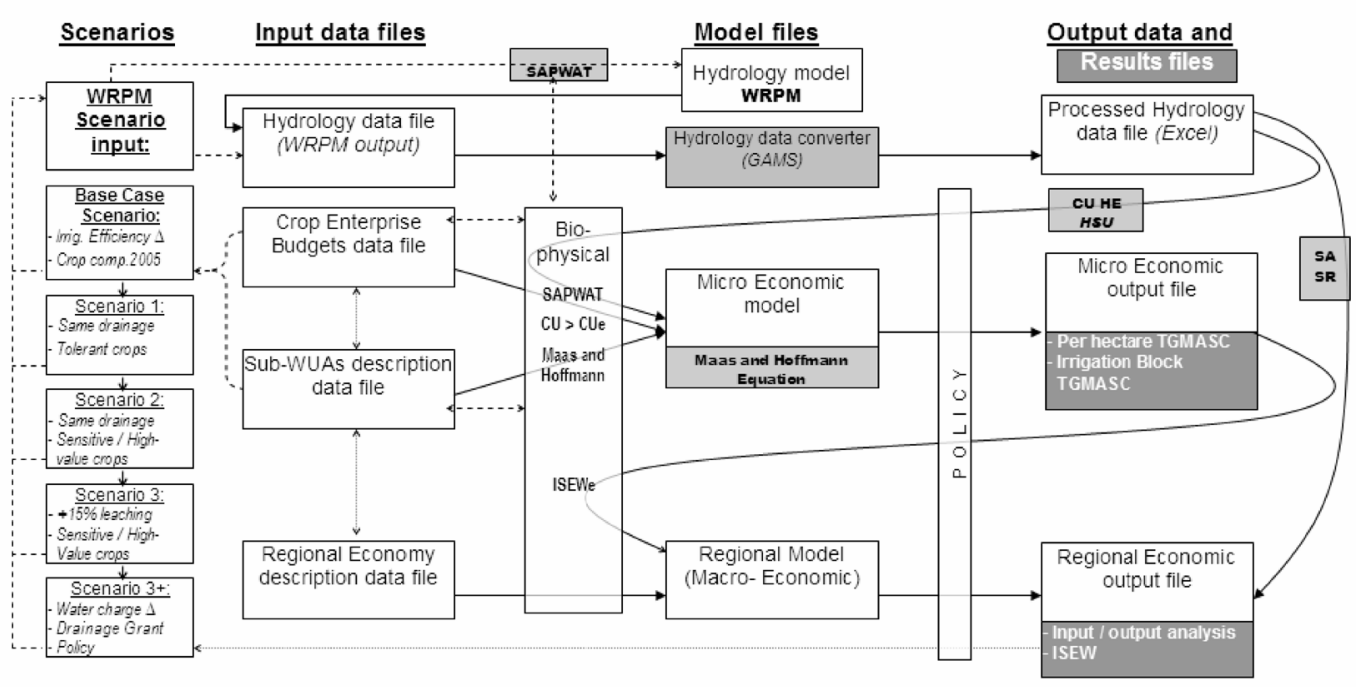

\section{Figure 2}

The integrated conceptual framework

The spatial dimensions of the model are delineated to build from per hectare level crop enterprise budget (CEBs) to irrigation block level and further. The CEBs set up on a per hectare level are differentiated according to the various irrigation block characteristics. After determining the impact on yield on a gross margin per hectare level, the adjusted per hectare CEBs are multiplied by the irrigation block irrigable area to get irrigation block level CEBs. The assumption is that the irrigation block is one big farm, repeating exactly the same cropping combination for 15 years at the same 2005 base year crop prices. Irrigation blocks are combined into WUAs, and WUAs are combined to form the regional economic model.

The temporal dimensions of the model are delineated to monthly, annual and 15 year cumulative results. The model aims to simulate results over a range of 100 stochastic WRPM runs, giving the per-hectare financial impacts and possible range of financial results of salinity for different irrigation blocks per year and over 15 years. The primary data was collected mainly through expert panels and the secondary data from GWK and the WUA WMPs.

The mathematical specification of the model is an expansion of the per-hectare level CEBs; perhectare TGMASCs are expanded to irrigation block and WUA level TGMASC results for use in micro-level analysis and as inputs for the regional economic model. Farm level analysis incorporating the fixed cost component is not included in this study.

\subsection{Mathematical specification of the model}

The derivation of the saturated soil salinity, ECe $(\mathrm{mS} / \mathrm{m})$

One of the main data outputs of the hydrology model (WRPM) is factor CU ( $\mathrm{mg} / \mathrm{l})$, measuring the field level salt concentration in the upper soil zone, set up for each month $(t)$ over 15 years $(y)$ for each irrigation block $(s)$ and run with 100 stochastic variations $(\boldsymbol{s r})$. This data set needs to be converted to a saturated soil extract salinity concentration $\mathrm{CUe}(\mathrm{mg} / \mathrm{l})$, and from 
this, an electrical conductivity of the saturated soil paste, ECe $(\mathrm{mS} / \mathrm{m})$ is determined. These monthly ECe values then need to be converted to crop specific annual averages by working out the weighted average ECe based on the monthly crop water requirement and the ECe in each month. Thus

(1) $\boldsymbol{C U} \boldsymbol{e}_{t, s}=\left(\boldsymbol{C U _ { t , s }} \cdot \boldsymbol{H E} \boldsymbol{E}_{t}\right) / \boldsymbol{H S U}$

where $\mathrm{CUe}_{t, s}$ is the monthly saturated soil salinity concentration $(\mathrm{mg} / \mathrm{l})$ in the upper soil layer for each sub-WUA $(s)$ for each time period $(t)$

$\mathrm{CU}_{t, s} \quad$ is the monthly natural field level (un-saturated) soil salinity concentration $(\mathrm{mg} / \mathrm{l})$ in the upper soil layer for each sub-WUA $(s)$ for each time period $(t)$

$\mathrm{HE}_{t} \quad$ is the monthly $(t)$ effective soil water volume $(\mathrm{mm} / \mathrm{ha})$

HSU soil moisture storage capacity in the upper zone $(\mathrm{mm} / \mathrm{ha})=$ constant $400 \mathrm{~mm} / \mathrm{ha}$

(2) $\boldsymbol{E C e _ { t , s }}=\boldsymbol{C U} e_{t, s} / \boldsymbol{S C F}$

where $\mathrm{ECe}_{t, s}$ is the monthly ECe in the upper soil layer for each subWUA $(s)$ for each time period $(t)$

SCF is the TDS to EC salinity conversion factor $=$ constant 6.5 (Moolman \& Quibell, 1995)

(3) $E C c_{c, y, s}=\sum_{t, m} E C e_{t, s} * C W R_{c, m}$ where $\mathrm{ECc}_{c, y, s}$ is the weighted average ECe for each crop $(c)$ for each year $(y)$ and in each irrigation block $(s)$

$\mathrm{CWR}_{c, m} \quad$ is the crop water requirement percentage, monthly $(\boldsymbol{m})$ for all crops $(c)$

Setting up the salinity-yield functions using the Maas and Hoffmann (1977) equation

The electrical conductivity of the saturated zone, ECe $(\mathrm{mS} / \mathrm{m})$ is inputted into the Maas and Hoffmann (1977) equation to determine the impact on yield in the micro-economic model. The $\mathrm{ECc}_{\mathrm{c}, \mathrm{y}, \mathrm{s}}$ calculated in Equation 3 is the main input for the Maas and Hoffmann (1977) equation, together with crop salinity threshold (Thrsh) and crop salinity gradient (Grad) values. Thus:

\section{(4) $T h r s h L F_{c}=T h r s h_{c}^{*}\left(1+L F_{s}\right)$}

where $\operatorname{ThrshLF}_{c}$ is the crop (c) specific salinity threshold value adjusted for leaching

Thrsh $_{c} \quad$ is the crop (c) specific salinity threshold value (assumed constant for all irrigation blocks)

$\mathrm{LF}_{\mathrm{s}} \quad$ is the leaching fraction (per cent additional water) applied in each irrigation block $(s)$

(5) $Y f_{c, y, s}=\left\{100-\operatorname{Grad}_{c} *\left(E C c_{c, y, s}-\right.\right.$ ThrshLF $\left.)\right\} / 100$ where $\mathrm{Yf}_{c, y, s}$ is the fraction of maximum yield obtainable when subject to salinity $\mathrm{ECc}_{\mathrm{c}, \mathrm{ys} s}$

ThrshLF $_{c} \quad$ is the crop (c) specific salinity yield reduction threshold value adjusted for leaching

$\operatorname{Grad}_{c} \quad$ is the crop (c) specific salinity yield reduction gradient (assumed constant for all irrigation blocks)

$\mathrm{ECc}_{c, y, s}$ is the weighted average ECe for each crop $(\boldsymbol{c})$ in each year $(y)$ for each irrigation block $(s)$

(6) $Y s_{c, y, s}=Y f_{c, y, s} * Y m_{c}$

where $\mathrm{Ys}_{c, y, s}$ is the new yield (ton / ha) subject to salinity

$\mathrm{Yf}_{c, y, s} \quad$ is the fraction of maximum yield obtainable when subject to salinity $\mathrm{ECc}_{\mathrm{c}, \mathrm{y}, \mathrm{s}}$

$\mathrm{Ym}_{c} \quad$ is the max potential / physiological yield (ton / ha)

\section{SMsim micro-cconiomic model core}

The core of the model is Equation 7 where reduced crop yield due to salinity $\left(\mathrm{Ys}_{\mathrm{c}, \mathrm{y}, \mathrm{s}, \mathrm{r}}\right)$ is related to a per hectare financial value TGMASCh$_{c, y, s, r:}$ 


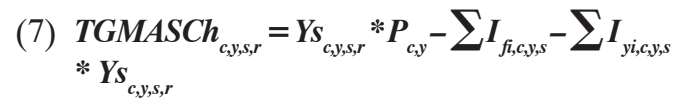
where TGMASCh $h_{c, y, s, r}$ is the TGMASC per hectare $(\mathrm{R} / \mathrm{ha})$ for each crop $(\boldsymbol{c})$ in each year $(y)$ and in each irrigation block $(s)$ for each stochastic run $(r)$

$\mathrm{Ys}_{c, y, s, r} \quad$ is the new yield (ton / ha) subject to salinity for each stochastic run $(r)$

$\mathrm{P}_{c, y, s} \quad$ are the different crop (c) prices $(\mathrm{R} /$ ton $)$ in each year $(\boldsymbol{y})$ and in each irrigation block $(s)$

$\mathrm{I}_{f i, c, y, s} \quad$ are the fixed input costs $(f i)$ i.e. seed, fertilizer, chemicals, etc. (R/ha), for the different crops (c) which remain unchanged in each year $(y)$, but which can change between irrigation blocks $(s)$.

$\mathrm{I}_{y, c, y, s} \quad$ are the yield dependant production costs $(y i)$ i.e. harvesting, packaging, transport, etc. (R/ton), for the different crops $(c)$ in each year $(y)$ and in each irrigation block $(s)$.

(8) TGMASCs $s_{y, s, r}=\sum_{c} \operatorname{TGMASCh}_{c, y, s, r} * S A_{s} *$ $\boldsymbol{C P}_{c, s}$

where TGMASCs $_{c, y, s, r}$ is the irrigation block TGMASC (R) of crop (c) planted per irrigation block $(s)$ for each stochastic run $(r)$

$\mathrm{SA}_{\mathrm{s}} \quad$ is the irrigation block irrigated area

$\mathrm{CP}_{c, s} \quad$ is the percentage of crop (c) planted per irrigation block

(s) (= per cent planted per representative farm )

(9) $\boldsymbol{T G M A S C} \boldsymbol{w} \boldsymbol{r}_{y, s, r}=\sum_{s r} \boldsymbol{T G M A S C s _ { y , s s . r }}$ where TGMASCwr Th,s,r $_{\text {is }}$ is the OR-WUA level (sr) annual TGMASC for each stochastic run $(r)$

(10) $T G M A S C w v_{y, s, r}=\sum_{s v} T G M A S C s_{y, s, r}$ where TGMASCwv Ths, $_{\text {, }}$ is the OV-WUA level (sv) annual TGMASC for each stochastic run $(\boldsymbol{r})$
(11) $T G M A S C r_{y, r}=\sum_{s} T G M A S C s_{y, s, r}$ where $\mathrm{TGMASCr}_{y}$ is the regional level TGMASC per year

(12) TGMASCrc $_{r}=\sum_{y} \boldsymbol{T G M A S C r}_{y, r}$

where TGMASCrc is the regional level TGMASC for the full number of years examined (15 years in this model)

$\mathbf{I}_{f i, c, y, s}$ and $\mathbf{I}_{y i, c, y, s}$ are run through to the macro model as individual components where the regional and secondary impact of each of the sectors supplying the inputs is determined.

For the sake of presenting the complete microeconomic level model, equations 8 to 12 are also included, but their results are not discussed in this paper. Equation 8 converts per hectare TGMASC to irrigation block level TGMASC by adding together the products of the per hectare TGMASCs, irrigation block irrigable areas (SA) and cropping percentage $(\mathrm{CP})$ for each irrigation block.

Equations 9 and 10 combine the OR-WUA and OV-WUA irrigation block sub-sets by summation into WUA level TGMASC.

Equation 11 calculates the array of annual TGMASC for each of the 100 stochastic model runs $(\boldsymbol{r})$ and Equation 12 calculates the 15 year cumulative TGMASC for each of the 100 stochastic model runs $(\boldsymbol{r})$.

\section{5}

\section{Main results}

In Table 1, the base-case (representing the status quo) per hectare TGMASC $(\mathrm{R} / \mathrm{ha})$ is subtracted from the maximum Scenario 3 TGMASC (R/ha) which has yield forced to 100 per cent (Scen3 100 per centYield), representing a theoretical top level of productivity achievable without the constraint of salinity, to give an indication of the total per hectare cost of salinisation (net benefit forgone due to salinity). Taking into consideration the simplifying assumptions of the model, simulated results indicate that the greatest loss due to salinity is experienced in the Lower Riet Irrigation Block (RloR) to the value of R6 962 per hectare per year, followed by Scholtzburg (Rszg) with R2596 and the Orange- 
Vaal Irrigation Block (Vall) with R2 218. This can provide a farmer in the specific irrigation block with a good indication of the per-hectare costs of poor drainage on his/her farm, and a scheme manager or regional policy maker an indication of where the problem is worst and where to direct resources.

\section{Table 1}

Per hectare average annual TGMASC (R) for all scenarios of all the irrigation blocks compared (real 2005 prices), based on 100 stochastic runs

\begin{tabular}{|l|c|c|c|c|c|}
\hline & RloR & Rscm & Rszg & Vall & TOTAL \\
\hline Sub-region area (hectares) & 3853 & 12335 & 641 & 7390 & 24219 \\
Base Case & $\mathbf{2 ~ 2 9 9 . 9}$ & $\mathbf{6 9 9 8 . 3}$ & $\mathbf{6 ~ 2 1 5 . 6}$ & $\mathbf{5} \mathbf{4 8 8 . 2}$ & $\mathbf{5} \mathbf{7 6 9}$ \\
Scen3 & 9190.4 & 8738.1 & 8811.0 & 7701.2 & 8496 \\
Scen3+ drainage repay & 8243.5 & 8520.5 & 8573.9 & 7359.5 & 8124 \\
Scen3 100\%Yield & 9262.3 & 8738.1 & 8812.0 & 7706.7 & 8509 \\
\hline Cost of salinisation (R/ ha / yr) & $\mathbf{6 9 6 2 . 4}$ & $\mathbf{1 7 3 9 . 8}$ & $\mathbf{2 5 9 6 . 3}$ & $\mathbf{2 ~ 2 1 8 . 4}$ & $\mathbf{2 7 3 9 . 3}$ \\
\hline R/ha gain from leaching 15\% & 5943.57 & 1522.23 & 2358.26 & 1871.30 & 2354.23 \\
Per ha annual cost of drainage (R/ha) & -3348.54 & -3348.54 & -3348.54 & -3348.54 & -3348.54 \\
\hline Soil Productivity gain (R/ha) & $\mathbf{3 6 1 3 . 8 6}$ & $\mathbf{- 1 6 0 8 . 7 4}$ & $\mathbf{- 7 5 2 . 2 4}$ & $\mathbf{- 1 ~ 1 3 0 . 1 4}$ & $\mathbf{- 6 0 9 . 2 4}$ \\
\hline
\end{tabular}

${ }^{1}$ The $100 \%$ yield scenario is a theoretical top benchmark used in calculating net benefit forgone

At an average cost of drainage per ha on medium to heavy soils of R30 000 per ha (in-between the cost of drainage for medium and heavy soils and slightly inflated for the average soil types irrigated in the study area, to include in the costs of drainage other secondary / hidden costs) a 15 year loan at 9 per cent interest will cost R3 722 per year to service; this is economically feasible in $\boldsymbol{R l o R}$, though not as convincing without an assistance grant in $\boldsymbol{R s z g}$ and Vall.

Implemented for the whole study area (all irrigation blocks combined), the total real cost (2005 basis) of salinisation over a period of 15 years is simulated at R995 million (see Table 2), a good benchmark to use to leverage funds for remediation action.

Figure 3 shows stochastic runs 001, 080 and 044 , to suggest the full spectrum of stochastic results for all 100 runs. These three runs most closely fit the $0.05,0.50$ and 0.95 percentile probabilities of occurrence. Table 2 is a sensitivity analysis expansion of Table 1 , listing instead of the financial results of the 0.50 percentile of all stochastic simulations, the actual stochastic simulation of the runs selected from Figure 3.

\footnotetext{
Note: drainage costs can range from R12 000-R15 000 on sandy soils ( $<15$ per cent clay), R20 000-R25 000 on Medium soils (15-35 per cent clay), and R30 000-R50 000 on heavy soils ( $>35$ per cent clay) according to Reinders and Van der Merwe, 2005.
} 


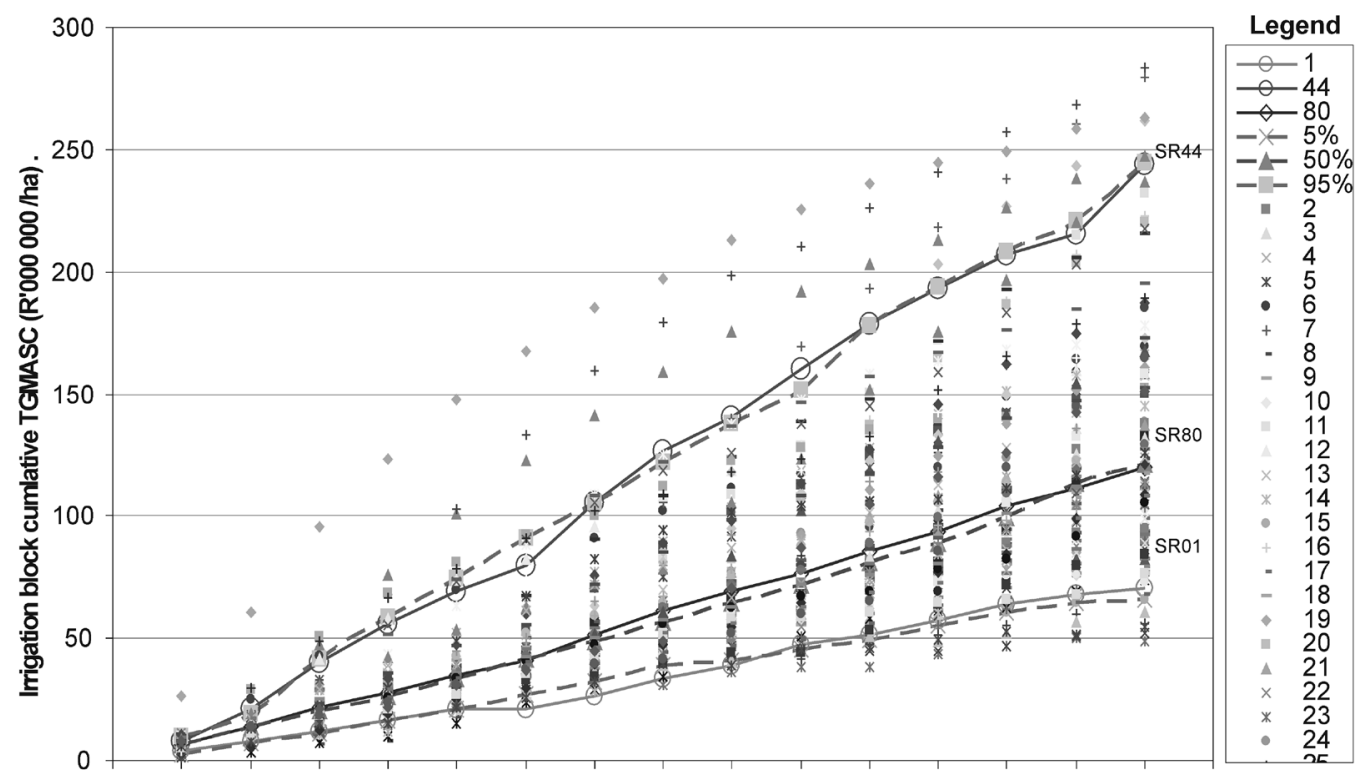

20042005200620072008200920102011201220132014201520162017201820192020 Years

\section{Figure 3}

Base-case scenario cumulative annual TGMASCs ( $\mathrm{R}^{\prime}$ mil) for the Lower Riet Irrigation Block showing the $0.05,0.50$ and 0.95 percentiles and most closely fitting stochastic runs 001, 080 and 044 respectively for 100 stochastic runs

\section{Table 2}

A summary of various SMsim model results comparing stochastic runs 001, 080 and 044 and the 0.50 percentile value of the 100 stochastic runs (2005 prices)

\begin{tabular}{|c|r|c|r|r|c|}
\hline \multicolumn{6}{|c|}{ Base case 15yr cumulative TGMASC (R'000 000) } \\
\hline & RloR & Rscm & \multicolumn{1}{|c|}{ Rszg } & \multicolumn{1}{c|}{ Vall } & \multicolumn{1}{c|}{ Tot. } \\
\hline $\mathbf{0 . 5 0 \%}$ & 133 & 1295 & 60 & 608 & $\mathbf{2 ~ 0 9 6}$ \\
$\mathbf{1}$ & 71 & 1290 & 56 & 625 & $\mathbf{2 0 4 3}$ \\
$\mathbf{8 0}$ & 120 & 1264 & 62 & 548 & $\mathbf{1 9 9 4}$ \\
$\mathbf{4 4}$ & 244 & 1329 & 64 & 615 & $\mathbf{2 ~ 2 5 2}$ \\
\hline
\end{tabular}

\begin{tabular}{|c|c|c|c|c|c|}
\hline \multicolumn{6}{|c|}{ Total cost of salinity ( $\mathrm{R}$ 'mil) } \\
\hline & RloR & Rscm & Rszg & Vall & Tot. \\
\hline $0.50 \%$ & 402 & 322 & 25 & 246 & 995 \\
\hline 1 & 465 & 326 & 29 & 229 & 1048 \\
\hline 80 & 416 & 353 & 23 & 307 & 1097 \\
\hline 44 & 291 & 288 & 21 & 239 & 839 \\
\hline
\end{tabular}

\begin{tabular}{|c|c|c|c|c|c|}
\hline \multicolumn{7}{|c|}{ Cost of salinity (R/ ha / yr) } \\
\hline & RloR & Rscm & Rszg & Vall & Ave. \\
\hline $\mathbf{0 . 5 0 \%}$ & 6962 & 1740 & 2596 & 2218 & $\mathbf{2 ~ 7 3 9}$ \\
$\mathbf{1}$ & 8040 & 1764 & 2968 & 2065 & $\mathbf{2 ~ 8 8 6}$ \\
$\mathbf{8 0}$ & 7190 & 1905 & 2364 & 2766 & $\mathbf{3 0 2 1}$ \\
$\mathbf{4 4}$ & 5036 & 1557 & 2132 & 2158 & $\mathbf{2 ~ 3 0 9}$ \\
\hline
\end{tabular}

\begin{tabular}{|c|c|c|c|c|c|c|}
\hline \multicolumn{6}{|c|}{ Scen3 \% CHANGE from base } & \multirow{2}{*}{$\begin{array}{l}\text { Change } \\
\text { (R'mil) }\end{array}$} \\
\hline & RloR & Rscm & Rszg & Vall & Ave. & \\
\hline $0.50 \%$ & 3.01 & 0.25 & 0.42 & 0.41 & 0.48 & 999 \\
\hline 1 & 6.53 & 0.26 & 0.51 & 0.37 & 0.51 & 1052 \\
\hline 80 & 3.44 & 0.28 & 0.37 & 0.56 & 0.55 & 1101 \\
\hline 44 & 1.18 & 0.22 & 0.32 & 0.39 & 0.37 & 844 \\
\hline
\end{tabular}




\begin{tabular}{|c|c|c|c|c|c|}
\hline \multicolumn{6}{|c|}{ R/ha gain from leaching 15\% } \\
\hline & RloR & Rscm & Rszg & Vall & Ave. \\
\hline $\mathbf{0 . 5 0 \%}$ & 5944 & 1522 & 2358 & 1871 & $\mathbf{2 3 5 4}$ \\
$\mathbf{1}$ & 7009 & 1546 & 2729 & 1719 & $\mathbf{2 4 9 9}$ \\
$\mathbf{8 0}$ & 6165 & 1688 & 2126 & 2422 & $\mathbf{2 6 3 6}$ \\
$\mathbf{4 4}$ & 4030 & 1339 & 1894 & 1809 & $\mathbf{1 9 2 5}$ \\
\hline
\end{tabular}

\begin{tabular}{|c|c|c|c|c|c|}
\hline \multicolumn{6}{|c|}{ Soil productivity gain (R/ha) } \\
\hline & RloR & Rscm & Rszg & Vall & Ave. \\
\hline $\mathbf{0 . 5 0 \%}$ & 4997 & 1305 & 2121 & 1530 & $\mathbf{1 9 8 2}$ \\
$\mathbf{1}$ & 6060 & 1328 & 2492 & 1378 & $\mathbf{2 1 2 7}$ \\
$\mathbf{8 0}$ & 5222 & 1470 & 1888 & 2080 & $\mathbf{2 ~ 2 6 4}$ \\
$\mathbf{4 4}$ & 3081 & 1122 & 1657 & 1467 & $\mathbf{1 5 5 3}$ \\
\hline
\end{tabular}

6

\section{Summary and conclusions}

The necessity of drainage is unquestionable, as the costs of salinisation estimated in the study show. To calculate to what level farmers can sustainably afford to pay for drainage themselves, the current/potential costs of salinisation need to be subtracted from the financial benefits of drainage.

Simulated financial results in Table 2 show that the greatest loss due to salinity is experienced in the Lower Riet Irrigation Block (RloR), to the value of R6 962 per hectare per year, followed by Scholtzburg (Rszg) with R2 596 and the Orange-Vaal Irrigation Block (Vall) with R2 218. Implemented for the whole study area (all irrigation blocks combined), the total real cost (2005 basis) of salinisation over a period of 15 years is estimated at R955 million (Table 2), a good benchmark to use to leverage funds to budget for a programme of remediation actions.

These results present an overwhelming case for the full sustainability ("green box") grant assistance of additional irrigation drainage in the interest of increased sustainable regional socio-economic welfare.

The results also suggest that caution is necessary when developing any new irrigation scheme, so that sufficient provision is made for

\begin{tabular}{|c|c|c|c|l|l|r|}
\hline \multicolumn{5}{|c|}{ Scen3+ \% CHANGE from base } & Change \\
$\left(\mathbf{R}^{\prime} \mathbf{m i l}\right)$
\end{tabular}

\begin{tabular}{|c|c|c|c|c|c|r|}
\hline \multicolumn{5}{|c|}{ Scen3 100\% CHANGE from base } & $\begin{array}{r}\text { Change } \\
\text { (''mil) }\end{array}$ \\
\hline & RloR & Rscm & Rszg & Vall & Ave. & \\
\hline $\mathbf{0 . 5 0 \%}$ & 3.03 & 0.25 & 0.42 & 0.4 & $\mathbf{0 . 4 7}$ & $\mathbf{9 9 5}$ \\
$\mathbf{1}$ & 6.58 & 0.25 & 0.51 & 0.37 & $\mathbf{0 . 5 1}$ & $\mathbf{1 0 4 8}$ \\
$\mathbf{8 0}$ & 3.47 & 0.28 & 0.37 & 0.56 & $\mathbf{0 . 5 5}$ & $\mathbf{1 0 9 7}$ \\
$\mathbf{4 4}$ & 1.19 & 0.22 & 0.32 & 0.39 & $\mathbf{0 . 3 7}$ & $\mathbf{8 3 9}$ \\
\hline
\end{tabular}

irrigation drainage, in the form of networks of drains and of canals and storage reservoirs to capture, control and manage the saline irrigation return flows from the drains so as not to create a downstream externality on other irrigation farmers, urban and/or industrial water users and the environment.

7

\section{Recommendations}

The main recommendations of this research are the following:

- Drainage installation for facilitating leaching needs to be promoted in the Orange-Vaal WUA (Vall) and especially in the Lower Riet $(\boldsymbol{R l o R})$ irrigation blocks in the study area. 10 per cent and 20 per cent of RloR and Vall irrigation blocks' irrigable area respectively need to be drained. The costs of drainage, which can be factored into irrigators' water tariffs, is less that the additional financial benefits derived from the drainage, and should therefore be acceptable to farmers. The figures should however be checked with a detailed survey and feasibility study.

- If the Rscm and Rszg irrigation blocks are to be drained, before salinity builds up to levels which will result in financial losses, at least an assistance grant for at least 50 per cent of the total drainage costs is needed to make 
the option financially viable and acceptable for the irrigators.

- Just as in an environmental management plan, remedial action for possible environmental and unsustainable practises must be planned and budgeted for at initialisation. The results of this study confirm the necessity of planning and installing drainage before the implementation of any new scheme (such as Oppermansgronde for example).

- The improvement of agricultural productivity arising from increased investment in irrigation drainage far outweighs the costs of this drainage, and has a positive ripple effect throughout the economy. Financial support from the national government can thus be motivated to provide sustainability assistance grants to farmers.

Other recommendations that could be implemented or initiated by the Department of Agriculture, WUAs, GWK, etc. in the irrigation areas include:

- Subsidised agricultural extension/technical services to regularly measure, archive and communicate soil salinity status, trends and threats;

- Programmes to promote the taking of soil salinity status readings by fertilizer companies when they conduct soil analyses and make fertilization recommendations;

- Programmes to oromote inquiry into the salinity status of soils when purchasing irrigation land; and

- Programmes to increase awareness among insurance companies of the potential increased crop risk on salinised soils if not managed properly.

These salinity awareness programmes must be coupled with a centralised soil salinity database to facilitate the accumulation of soil salinity data for better policy analysis and research in the future, as one of the limitations identified in this study is a shortage of historical soil salinity data.

\section{Acknowledgement}

The authors wish to acknowledge the South African Water Research Commission (WRC) for funding this project and the paper reviewers for their thorough work.

\section{References}

1 ARMOUR, R.J. \& VILJOEN, M.F. (2002) “The economic impact of changing water quality on irrigated agriculture in the lower Vaal and Riet rivers", WRC Report No.947/1/02, Water Research Commission: Pretoria.

2 CAI, X.; MCKINNEY, D.C. \& ROSEGRANT, M.W. (2003) "Sustainability analysis for irrigation water management in the Aral Sea region," Agricultural Systems, 76(3): 1043-1066.

3 COWEN, R. (2002) "Chapter 17: Ancient irrigation," Class Notes for Geology 115. http://www-geology. ucdavis.edu/ GEL115/115CH17oldirrigation. html. (Last accessed 16 October 2007).

4 COHEN, M.J. \& HYUN, K.H. (2006) "HAZARD: the future of the Salton Sea with no restoration project", Pacific Institute Report, http://www.pacinst.org/reports/saltonsea/index. htm. (Last accessed 16 October 2007).

5 KHAN, S.; TARIQ, R.; YUANLAI, C. \& BLACKWELL, J. (2004) "Can irrigation be sustainable?" In Fischer, T. et al. (eds.) New Directions for a Diverse Planet: Proceedings for the 4th International Crop Science Congress, Brisbane, Australia, 26 September- 1 October 2004. The Regional Institute Ltd.: Gosford http://www. cropscience.org.au/icsc2004/symposia/1/7/1399 shahbazkhan.htm (Last accessed 16 October 2007).

6 MAAS, E.V. \& HOFFMANN, G.J. (1977) "Crop salt tolerance: current assessment", ASCE Journal of Irrigation and Drainage, 103(2): 115-134.

7 MCKINNEY, D.C.; CAI, X.; ROSEGRAANT, M.W.; RINGLER, C. \& SCOTT, C.A. (1999) "Modelling Water resource management at the basin level: Review and future directions", SWIM

Paper 6, International Irrigation Management Institute System-Wide Initiative on Water Management, Colombo: Sri Lanka. http://www. $\underline{\text { k.iwmi.org/pubs/SWIM/index.htm (Last accessed }}$ 16 October 2007).

8 MOOLMAN, J. \& QUIBELL, G. (1995) "Salinity problems at the Douglas Weir and Lower Riet River", Institute for Water Quality Studies - DWAF. Report No N/C900/29/DIQ1495, Department of Water Affairs \& Forestry: Pretoria. 
9 PERRY, J. \& VANDERKLEIN, E. (1996) Water Quality: Management of a Natural Resource. Blackwell Science: Massachusetts.

10 VAN SCHILFGAARDE, J. (2004) "Irrigation - A blessing or a curse?" Agricultural Water Management, 25(3): 203-219.

11 VAN VEELE, M. (2004) "Modder and Riet River catchment management strategy: project steering committee meeting No.2. Presentation", 14 October, Bloemfontein. Unpublished report.

12 VILJOEN, M.F; ARMOUR, R.J.; OBERHOLZER, J.L.; GROSSKOPF, M.; VAN DER MERWE, B. \& PIENAAR, G. (2006) "Multi-dimensional models for the sustainable management of water quantity and quality in the Orange-Vaal-Riet Convergence System", WRC Report No. 1352/1/06, Water Research Commission: Pretoria.

13 VOLSCHENK, T.; FEY, M.V. \& ZIETSMAN, H.L. (2005) Situation analysis of problems for water quality management in the lower Orange river region with special reference to the contribution of the foothills to salinisation", WRC Report Number: 1358/1/05, Water Research Commission: Pretoria.

14 WICHELNS, D. (1999) "An economic model of waterlogging and salinization in arid regions", Ecological Economics, 30(3): 475-491.

\section{Personal communications:}

* REINDERS, F. (2005) Personal communication via e-mail on the costs of artificial drainage installation. reindersf@arc.agric.za Agricultural Research Council - Institute for Agricultural Engineering: Silverton.

* VAN DER MERWE, J. (2005) Personal communication via telephone on the costs of artificial drainage installation. CEDARA Agricultural College and Experimintal Farm Tel: +27034 4131370 . 